3D ground model development for an active landslide in Lias mudrocks using geophysical, remote sensing and geotechnical methods

\footnotetext{
A.J. Merritt ${ }^{[1]}$, J.E. Chambers ${ }^{[2]}$, W. Murphy ${ }^{[1]}$, P.B. Wilkinson ${ }^{[2]}$, L.J. West ${ }^{[1]}$, D.A. Gunn ${ }^{[2]}$, P.I. Meldrum $^{[2]}$, M. Kirkham ${ }^{[2]} \&$ N. Dixon ${ }^{[3]}$

* Corresponding Author. E-mail address: eeam@leeds.ac.uk (A.J. Merritt) Tel.: +44(0) 1133434696

${ }^{[1]}$ School of Earth \& Environment, Earth \& Environment Building, University of Leeds, Woodhouse Lane, West Yorkshire, LS2 9JT, UK.

${ }^{[2]}$ British Geological Survey, Environmental Science Centre, UK

${ }^{[3]}$ School of Civil and Building Engineering, Loughborough University, Leicestershire, LE11 2TU, UK
} 


\title{
3D ground model development for an active landslide in Lias mudrocks using geophysical, remote sensing and geotechnical methods
}

\author{
A.J. Merritt ${ }^{[1]} *$, J.E. Chambers ${ }^{[2]}$, W. Murphy ${ }^{[1]}$, P.B. Wilkinson ${ }^{[2]}$, L.J. West ${ }^{[1]}$, D.A. Gunn ${ }^{[2]}$, P.I. \\ Meldrum ${ }^{[2]}$, M. Kirkham ${ }^{[2]} \&$ N. Dixon ${ }^{[3]}$ \\ * Corresponding Author. E-mail address: eeam@leeds.ac.uk (A.J. Merritt) Tel.: +44(0) 1133434696 \\ ${ }^{[1]}$ School of Earth \& Environment, Earth \& Environment Building, University of Leeds, Woodhouse \\ Lane, West Yorkshire, LS2 9JT, UK. \\ ${ }^{[2]}$ British Geological Survey, Environmental Science Centre, UK \\ ${ }^{[3]}$ School of Civil and Building Engineering, Loughborough University, Leicestershire, LE11 2TU, UK
}

\begin{abstract}
A ground model of an active and complex landslide system in instability prone Lias mudrocks of North Yorkshire, UK is developed through an integrated approach, utilising geophysical, geotechnical and remote sensing investigative methods. Surface geomorphology is mapped and interpreted using immersive three-dimensional (3D) visualisation software to interpret airborne LiDAR data and aerial photographs. Subsurface structure is determined by core logging and three-dimensional (3D) electrical resistivity tomography (ERT), which is deployed at two scales of resolution to provide a means of volumetrically characterising the subsurface expression of both site scale (tens of metres) geological structure, and finer (metre to sub-metre) scale earth-flow related structures. Petrophysical analysis of the borehole core samples is used to develop relationships between the electrical and physical formation properties, to aid calibration and interpretation of 3D ERT images. Results of the landslide investigation reveal that an integrated approach centred on volumetric geophysical imaging successfully achieves a detailed understanding of structure and lithology of a complex landslide system, which cannot be achieved through the use of remotely sensed data or discrete intrusive sampling alone.
\end{abstract}

\section{Introduction}

\subsection{Nature of the problem/motivation}

Landslides are complex, strongly heterogeneous natural phenomena. A considerable number of landslide types exist, exhibiting varying states, distributions and styles of activity (Cruden 1996). If a better understanding of landslide internal processes is to be achieved, firstly, an understanding of landslide internal structure is required. Detailed information regarding landslide internal structure, lithological properties and relationships can be displayed in the form of a ground model. The principal use of a ground model is to inform about the range of possible subsurface conditions that exist at the site, knowing the geological processes that formed the ground beneath the site (McDowell et al. 2002; Fookes 1997; Griffiths et al., 2012) and are commonly presented as a threedimensional block model. Ground model development pulls data together from many information streams; from surface characterisation methods, such as geomorphological mapping using LiDAR, to subsurface characterisation methods, including borehole logging and geophysical surveys. 
Much research is concerned with rapid characterisation of landslides using aerial photography or remote sensing methods, such as Digital Photogrammetry, LiDAR and InSAR (de Bari et al. 2011; Perrone et al. 2006; Jaboyedoff et al. 2012; Colesanti and Wasowski 2006; Baldo et al. 2009; Dewitte et al. 2008). These methods rely on surface expression - such as slope angle or morphology - to ascertain the spatial extent and type of landslide. However, they provide very little or no information about internal landslide structure. Conversely, conventional intrusive investigations, such as sampling and borehole inclinometers, offer ground-truth data at high resolution, but implementing such methods over a large, inherently unstable feature such as a landslide is both costly and labour intensive. Geophysical methods are therefore being increasingly applied (Jongmans and Garambois, 2007) as a means of producing high resolution volumetric information, which can be sensitive to both subsurface structure and lithology, making full three-dimensional (3D) characterisation of the subsurface possible and permitting 3D ground model development.

Geoelectrics are a class of geophysical methods that can bridge the gap between intrusive subsurface investigative methods and remote sensing for ground surface characterisation in the context of landsliding. The main benefits of geoelectrical imaging methods are two-fold. Firstly, they employ lightweight equipment (relative to drill rigs) and are minimally invasive, and result in little ground disturbance. Secondly, they provide spatial and volumetric subsurface information, as opposed to conventional intrusive ground investigative techniques, such as core sampling, which provide discrete, one-dimensional information for a given location.

In the last decade, electrical resistivity tomography (ERT) has become a standard geophysical imaging technique for environmental and engineering investigations (Reynolds, 2011) and is routinely implemented to locate the failure surfaces within landslide systems (Jongmans and Garambois 2007). The method can be effectively applied to ground investigation due to its sensitivity to lithological variation, principally, quartz and clay content, but also water content and pore-fluid conductivity (Telford et al. 1990). When applied to landslides, ERT is implemented to highlight lithological variations and boundaries, as well as geological discontinuities such as faults, drainage channel systems and other structural features (Lebourg et al. 2005). Because ERT provide indirect subsurface information, it is most appropriately applied alongside other techniques for calibration and validation.

Two-dimensional electrical resistivity tomography is extensively applied to landslide investigation due to its capacity to model landslide geometries such as body thickness, lateral extent and position of slip surfaces in a number of varying geological settings (Perrone et al. 2004; Lapenna et al. 2003; Godio et al. 2006; Jomard et al. 2007; Sass et al. 2008; Schmutz et al. 2009; Colangelo 2008; Bichler et al. 2004). In contrast, three-dimensional ERT (3D-ERT) is rarely implemented to investigate landslide systems; this could be attributed to several factors, principally the additional field and processing effort that is required relative to 2D ERT. However, for complex 3D structures, which landslides typically are, a fully volumetric 3D approach is more appropriate. A number of examples of $3 \mathrm{D}$ landslide studies exist in the literature, a brief summary of the most relevant is provided below.

A 3D resistivity survey was performed at a coastal setting by Udphuay et al. (2012). They implemented 3D ERT to assess the vulnerability of a cliff section in Normandy to cliff collapse. The various formations present - identified based on variable resistivity response - were assigned 
different mass movement potentials, despite the presence of extreme topography and cultural signals.

Heincke et al. (2010) studied The Åknes rockslide in western Norway using a combined 3D geoelectrical and seismic tomographic approach. Seismic low velocity zones coincident with low resistivity anomalies were associated with drained (air-filled) and water-filled parts of tension cracks. Low-velocity and low-resistivity anomalies are explained by elongated tension cracks that are dry close to the surface and water-saturated at greater depths and correspond to tension cracks previously located and mapped in the region.

Pyroclastic cover material subject to debris-flow processes were investigated through highresolution 3D resistivity surveys by Di Maio and Piegari (2011) in the Sarno Mountains of Campania Region, Southern Italy. These landslides are periodically triggered by critical rainfall events, hence, subsurface water content distribution is a key factor influencing the stability of the investigated lithologies. Laboratory determined petrophysical relationships were used to determine subsurface soil moisture content from ERT images.

A semi-empirical approach to slope stability analysis of pyroclastic cover material was proposed by Di Maio and Piegari (2012). They introduced a geophysical factor of safety in terms of in-situ electrical resistivity and slope angle. They outlined the benefits of applying 3D ERT, a volumetric geophysical technique to assess slope stability as opposed to conventional physical analyses whose input parameters are determined through point-sample testing and laboratory tests performed on small volume soil samples, which are unrepresentative of the wider slope.

The La Clapiere landslide in the South East French Alps is responsible for large-volume mass movement of metamorphic bedrock. Lebourg et al. (2005) applied 2D, 3D and 4D ERT to investigate the rupture processes taking place within deep seated landslides. The investigation successfully located the principal slipping surface of La Clapiere landslide as well as the draining system in terms of identifying vertical draining structures and perched water table in superficial moraine deposits.

\subsection{Aims \& objectives}

This paper aims to develop a detailed landslide ground model using an integrated 3D geophysical and geotechnical approach for a landslide in Lias mudrocks. The landslide is located within the Whitby Mudstone Formation (WMF) on a valley side, and is typical of many inland slope failures in Lias mudrock.

Our study site has the advantage of being the focus of previous geophysical investigation (Chambers et al., 2011), in which multiple geophysical reconnaissance methods were applied and assessed. Here we focus on the most effective geophysical methodology considered in the previous study, 3D ERT, to develop a detailed ground model based on additional high resolution volumetric resistivity imaging work, detailed core logging and testing, direct calibration of ERT data through laboratory analysis and remote sensing visualisation techniques. We outline the methodology for ground model development, and critically assess the benefits of incorporating 3D ERT into landslide investigation at different image resolutions and regions of the landslide. There is no other example of ground model development in the Whitby Mudstone Formation in the literature, and very few examples of integrated ground investigations centred on the use of 3D ERT. 


\section{Site background}

\subsection{Geology \& Geomorphology}

The research area is located 4 miles west of the market town of Malton, North Yorkshire, UK. The field site itself is located on a south-facing hill slope used as pasture land. It is bounded to the north, south and east by hedged arable land - mostly wheat and rape - and by mature woodland to the west. Figure 1 provides an overview map, which shows the geology of the field site and surrounding area.

Beyond the base of the field site hill slope is a wide topographic embayment called Sheriff Hutton Carr, to the south of which is a ridge composed of Lower Jurassic formations. During the Devensian much of Northern Britain was covered in a thick ice sheet. Sheriff Hutton Carr was the site of an icemarginal lake, responsible for depositing lacustrine-derived material in the lowland between Hollin Hill slope and the ridge (Ford, in press).

The hill slope is composed of four geological formations of Lower and Middle Jurassic Age. The base of the Hollin Hill slope comprises Redcar Mudstone Formation (RMF) and marks the oldest formation at the field site, and is overlain by Staithes Sandstone Formation (SSF) which gives way to Whitby Mudstone Formation (WMF), with Dogger Formation (DF) capping the hill slope. Dogger Formation is the lowermost formation of the Ravenscar Group of the Middle Jurassic and has an erosional base over most of the Yorkshire Basin (Powell 1984; Rawson 1995).

Lias Group formations - in particular WMF - are prone to slope instability. The study site covers an area of roughly $450 \mathrm{~m}$ by $200 \mathrm{~m}$, and a change in elevation of $\sim 50 \mathrm{~m}$ from the base to the top of the slope, and contains a complex landslide system that exhibits a variety of landslide types and activity. The landslide system extends many hundreds of metres along the hill slope beyond the limits of the study site and has been previously described as a slow to very slow moving multiple earth slide earth flow (Chambers et al. 2011). A site plan and aerial photograph of the field site is presented as Figure 2, and shows the locations of installed monitoring equipment, drilled boreholes and of the major geological formation boundaries which outcrop at the site.

\subsection{Previous investigations}

The landslide at Hollin Hill has been previously reconnoitred using several geoelectrical geophysical methods including electrical resistivity tomography (2D and 3D), self-potential profiling, mapping and tomography and mobile resistivity mapping (Chambers et al. 2011). A 3D ERT was performed at the site of an area which extends from the back scarp to the toe of the landslide and encompassed the most active areas of the landslide system. The results of 3D ERT model show that the succession from low resistivity RMF to more resistive SSF through to less resistive Whitby Mudstone Formation is clearly displayed, as is the general $5^{\circ}$ North dip trend of the surveyed formations. Mobile resistivity mapping was undertaken using the automated profiling technique (ARP) - developed by Geocarta $\mathrm{SA}$, France - with the aim of producing very near surface property maps. This technique produced a map of apparent resistivity and informs about soil spatial property variation attributed to texture, clay content, stoniness and depth to substratum. Groundwater movement was investigated through the identification of streaming potentials in the subsurface using self-potential profiling, mapping and tomography. 3D self-potential tomography reveals the nature of drainage and surface run-off on the slope. Interpretation of 3D SP tomograms reveals that infiltration and drainage into SSF is 
occurring. The lack of strong positive charge occurrence probability in the WMF suggests that rainfall runs off the relatively impermeable formation and infiltrates SSF further downslope.

\section{Methodology}

This paper builds on previous investigations at the research site in several key areas. ERT surveys are presented at different resolutions to display the internal structure of the landslide system and display improved detail afforded by higher resolution imaging. New high-resolution ERT images of the most active area of the landslide are interpreted using detailed core logs, and laboratory sample analysis; in particular, laboratory analyses are used to establish relationships between resistivity and lithologies of the key formations (i.e. WMF and SSF). Surface and subsurface observations of movement are used to indicate the distribution and rate of slope movements and the location of slip surfaces. The latest Digital Terrain Model (DTM) data generated from airborne LiDAR is analysed alongside aerial photographs using GeoVisionary, an immersive 3D graphical visualisation software package, designed to allow the user to undertake virtual fieldwork in which even subtle geomorphologic features can be identified (Jordan et al., 2009). This combination of high resolution surface and subsurface data is used here to develop a site-specific ground model.

\subsection{Surface characterisation}

\subsubsection{Aerial LiDAR/GeoVisionary}

Light Detection and Ranging (LiDAR) optical remote sensing methods are implemented to produce high-resolution Digital Elevation Models (DEMs). An airborne LiDAR survey of Hollin Hill was performed January 2011, and GeoVisionary 3D Stereographic Software System used to visualise the resulting survey dataset. GeoVisionary is a software package developed specifically for virtual field reconnaissance (Jordan et al. 2009). The software is capable of visualising high-resolution spatial data containing geomorphologic features, such as changes and breaks in slope, which can be digitised directly onto the 3D digital elevation model. The geomorphological map produced at Hollin Hill shows the distribution of landslide features, breaks in slope and other landforms throughout the field site.

\subsubsection{GPS Survey of Peg Positions}

A series of 45 surveying pegs were inserted approximately $0.3 \mathrm{~m}$ into the top soil at the field site in a rectangular-shaped grid as shown on the base map, Figure 2 . By repeatedly surveying the position of each peg periodically over a number of years it has been possible to determine both the landslides rate of movement, its most active regions and its movement history since monitoring began in March 2008. The Leica System 1200 RTK-GPS (Real-Time Kinematic-Global Positioning System) is used to make repeat measurements of pegs installed at the field site. Accuracy of the system in kinematic mode (receiving real-time position corrections) is up to $10 \mathrm{~mm}$ (rms) horizontally and 20 $\mathrm{mm}$ vertically.

\subsection{Subsurface characterisation}

\subsubsection{D Electrical Resistivity Tomography (3D-ERT)}

Electrical resistivity tomography was performed on the landslide at two scales. The large-scale survey covered a region of the landslide system from the crown to beyond the landslide foot and toe, and is represented by the red rectangular area on the base map, Figure 2 . Electrode spacing was 
$4.75 \mathrm{~m}$ along-line and $9.5 \mathrm{~m}$ between lines, covering an area of $38 \times 147.25 \mathrm{~m}$. Data was acquired using the AGI Supersting R8 electrical resistivity survey system. Measurements of potential were made using a dipole-dipole configuration, with dipole sizes of 4.75, 9.5, 14.25 and $19 \mathrm{~m}(a=1-4)$ and dipole sizes $(n)$ of 1 to $8 a$. A complete set of reciprocal measurements was utilised for data quality assessment and editing (Dahlin and Zhou, 2004; Wilkinson et al., 2012).

The higher resolution ERT survey imaged an active flow lobe at a level of resolution closer to that of deposit heterogeneity (i.e. sub-metre rather than metre scale). A similar measurement configuration was employed, dipole-dipole, with dipole sizes of 1.0, 2.0, 3.0 and $4.0 \mathrm{~m}(a=1-4)$ and $n$ of 1 to $8 a$. Higher-resolution was achieved for the second survey by decreasing the electrode spacing of the second ERT survey by a factor of 5 to one metre along-line spacing and two metres between survey lines. A total 28 lines were performed, eleven- $31 \mathrm{~m}$ length surveys parallel to $y$-axis and seventeen$20 \mathrm{~m}$ surveys perpendicular to the $\mathrm{y}$-axis which were combined to produce a fully three-dimensional resistivity dataset. The high resolution survey covered an area of $31 \mathrm{~m}$ by $20 \mathrm{~m}$ using a grid of 32 by 21 electrodes.

Dipole-dipole measurements of resistance are made by four-point measurement, with two current and two potential electrodes. The reciprocal measurement $\left(\rho_{r}\right)$ of the transfer resistance $\left(\rho_{n}\right)$ is made by interchanging the current and potential dipoles. The Reciprocal Error for a given four-point measurement of resistance is defined as the percentage standard error in the average resistance measurement (average of transfer and reciprocal measurements) and is calculated:

$$
|\mathrm{e}|=100 \mathrm{x}\left|\rho_{\mathrm{n}}-\rho_{\mathrm{r}}\right| /\left(\rho_{\mathrm{n}}+\rho_{\mathrm{r}}\right)
$$

Chambers et al. (2011) reports the error handling method and values utilised for the large-scale ERT survey. The higher-resolution ERT survey of the flow region $92.9 \%$ of measurements had a reciprocal error of less than $1 \%$ and so, all data points greater than $1 \%$ reciprocal error were removed before inversion. After editing a total of more than $\mathbf{8 7 0 0}$ transfer resistance data points were inverted and an acceptable model convergence was achieved within four iterations of $1.83 \%$ mean absolute misfit error.

\subsubsection{Boreholes \& Geotechnical Testing}

During October 2009 a drilling campaign was undertaken using the Dando Terrier geotechnical percussion drilling rig and a total of nine boreholes performed, each to a depth of between $5 \mathrm{~m}$ and $7 \mathrm{~m}$. The decision was made to focus attention on the most active part of the landslide system within the field site, which exhibited the freshest landslide features (a sharp crown and main scarp and lightly vegetated flow deposits).

Three of the eight boreholes performed during the drilling campaign at Hollin Hill were logged to BS5930 (British Standards Institution, 1999) and index tested to BS1377 (British Standards Institution, 1993). Cores selected for logging and geotechnical index testing were subjected to the following: particle size distribution (fines content by x-ray sedigraph), moisture content and shear strength by hand vane. Also, a series of Atterberg Limit tests were performed, to give an insight into the consistency and behaviour of the WMF and SSF at various moisture contents (Head 2006), and xray diffraction (XRD) analysis was used to investigate clay mineralogy. Particle size distribution 
analyses were performed every $0.5 \mathrm{~m}$ until a lithology change was reached, in that case a PSD was performed either side of the lithological boundary. The positions of boreholes selected for logging and geotechnical index testing are shown on the field site basemap, Figure 2, with Boreholes 1 (BH1) and 7 (BH7) located on the western lobe and Borehole $5(\mathrm{BH} 5)$ on the eastern lobe. Boreholes were interpreted based on the results of detailed core logging, high-resolution core photographs and index testing into landslide deposit type and stable, in-situ material. Therefore, the 1-dimensional structure of the landslide system is known at three discrete regions, these interpreted core logs. Four divisions were used to classify the core in terms of lithology and internal structure; top soil, flow deposits, rotational slump deposits and in-situ Staithes Sandstone Formation.

\subsubsection{Borehole Inclinometer}

Periodically, borehole inclinometer measurements were made using an ITMSOIL vertical inclinometer system at boreholes $\mathrm{BH} 1, \mathrm{BH} 5$ and $\mathrm{BH} 7$, during 2009. Displacement readings were taken every $0.5 \mathrm{~m}$ within the casing to determine the depth, direction and magnitude of slip surface displacement over time.

\subsubsection{Core Resistivity and Cation Exchange Capacity}

Laboratory measurements of soil resistivity were made on core from $\mathrm{BH} 5$ and $\mathrm{BH} 7$, with the aim of aiding the differentiation between units and formations. The cores were halved - using a purposemade rock core cutting saw - by making an axial cut, along the full length of each one-metre core run. At 0.1 metre spacing a Decagon 5TE (Topp et al. 1980) soil moisture and bulk electrical conductivity $(\mathrm{EC})$ probe was inserted into the half core and bulk EC measured for the whole length of cores $\mathrm{BH} 5$ and $\mathrm{BH} 7$. The results of core resistivity measurements are presented along with the interpreted borehole logs in order to show the variation in electrical resistivity between soil units at Hollin Hill.

Electrical conductivity of soils is a function of several physical factors pertaining to the soil's mineralogy and structure. In a sand-rich soil the main physical factors affecting conductivity are the bulk conductivity of pore fluid, soil saturation, porosity and pore tortuosity. However, when dealing with clayey soils and rocks there is an additional factor, which is the propensity of the surface of clay minerals to conduct and therefore contribute to the bulk electrical conductivity of the soil (Revil 1998). Surface electrical conductivity is related to the CEC of the clay minerals present in soil, and therefore the greater number of cation exchangeable sites within the sand-clay soil mixture the higher the bulk conductivity of the soil. A series of 32 soil core samples from $\mathrm{BH} 5$ and $\mathrm{BH} 7$ were tested for CEC and a plot of core resistivity - measured using Decagon 5TE soil moisture sensor (described above) - versus CEC produced. These tests were used to differentiate between the major soil types on the basis of lithological properties (i.e. CEC) and resistivity, thereby establishing petrophysical relationships to aid the interpretation of the 3D resistivity images.

\section{Results and discussion}

\subsection{Surface expression}

The geomorphology map of Hollin Hill is shown in Figure 4. To the north of the site, an abrupt decrease in slope angle - highlighted by positive and negative break in slope - indicates the presence of the main scarp along with associated crown cracks as the landslide continues to retrogress 
northward. The back tilted nature of the head of the landslide is suggestive of rotational slumping. The main scarp can be traced east-west across the site; however it is the north-east region that appears to be currently most active. The existence of fresh, very shallow rotational slumps to the north-east is evidence that shallow slumping is taking place alongside less active and more extensive, deeper-seated slumping. Traversing south from the main scarp and beyond the fresh, shallow rotational slumps are a series of five or six subtle pairs of positive and negative breaks in slope. Each pair is separated by near-horizontal or slightly back tilted ground surface and are indicative of rotated slump blocks. The number of rotational slumps present across the landslide system appears to vary in the mid-hill slope region of the system. The eastern region of the site has more visible fresh slumps than the west suggesting that the eastern has recently experienced more slumping events compared to the west of the site.

The geomorphologic nature of the site transforms further south as approximately parallel breaks in slope give way to curved breaks in slope. The change in surface expression is attributed to a change in landslide type as rotational slumping seen in the mid- to upper- regions of the slope gives way to flowing, with several flows being active simultaneously. There are four regions of the landslide system where flows have developed and overridden slumped material. Each lobe of flow deposits is composed of previously slumped material and is comprised of several smaller flows - moving on multiple shear planes - which together form four distinct zones of accumulation throughout the field site. The zone of depletion of the landslide system lies between the main scarp to the north and the flow deposits further to the south. Above the two most easterly flow deposit lobes exists an area of relatively flattened and smoothed hill slope, this area is supplying displaced material to the currently active flow lobes.

\subsection{Rates and distribution of movement}

The results of the GPS survey are presented in Figure 3, which shows marker peg movement during the monitoring period. Typical rates of movement are in the order of a few tens of centimetres per year and are restricted to small areas towards the front of the earth flow lobes, with most of the marker pegs remaining static.

Inclinometer data (Figure 5) produced over a period of two months in 2009 (Oct-Dec 2009) at BH7 and a period of twelve months (Jan-Dec 2009) at BH1 show that the active slip surface of the flow lobes is at between $1.0 \mathrm{~m}$ and $1.5 \mathrm{~m}$ depth, indicating that the same flow lobe is moving at the two locations. Maximum shear surface displacements during the period of investigation by inclinometer at $\mathrm{BH} 1$ and $\mathrm{BH} 7$ are $25 \mathrm{~mm}$ and $15 \mathrm{~mm}$ respectively. BH5 inclinometer records show that a small amount of movement within the slumped deposits took place ( $2 \mathrm{~mm}$ of displacement), along with movement between $0.5 \mathrm{~m}$ and $1.0 \mathrm{~m}$ depth during the 2009 period of monitoring.

\subsection{Soil structure and types}

The results of core logging, index, resistivity and $\mathrm{CEC}$ testing from $\mathrm{BH} 1, \mathrm{BH} 7$ and $\mathrm{BH} 5$ are shown in Figure 5 . These indicate that below the top soil layer are three principal soil units.

The uppermost layer is composed of several flow deposits, each separated by narrow slip surfaces. $\mathrm{BH} 7$ and $\mathrm{BH} 1$ are both interpreted as comprising six flow deposits, in which inclinometer data indicates that movement is occurring along shear planes between $1.0 \mathrm{~m}$ and $1.5 \mathrm{~m}$ (see Section 4.2.). 
Flow shear planes were identifiable by core logging due to the existence of thin yellowish-brown clay layers, often found in conjunction with organic-rich horizons, decayed rootlets underlain by mottled grey, gleyed clay zones. Flow deposits of $\mathrm{BH} 1$ and $\mathrm{BH} 7$ show similarities in their particle size distributions as their upper $0.7 \mathrm{~m}$ is dominated by clay- and silt-sized material, below this depth until the contact with slump deposits is reached at $3.1 \mathrm{~m}$ - sand-sized material dominates.

With increased depth the clay-dominated and sand-dominated flow deposits give way to a series of rotational slump deposits. Slump deposits at $\mathrm{BH} 1$ and $\mathrm{BH} 7$ are distinctly heterogeneous, gravelly silty clay and clayey sandy silt being the most common soil types. Three slip surfaces are present in all three boreholes and are identifiable in soil core due to the existence of gravel-sized rip-up clasts, mostly composed of sub-angular, iron-stained clasts of sandstone. Where the formation is silt dominated shear surfaces exist as thin silt/clay rich layers, $10 \mathrm{~cm}$ in thickness. At greater depths, at $5.20 \mathrm{~m}$ and $4.90 \mathrm{~m}$ in $\mathrm{BH} 7$ and $\mathrm{BH} 1$ respectively the base of the slump deposits exist and the top of in-situ Staithes Sandstone Formation is reached. In the core, SSF is a firm to hard light olive grey to yellowish brown micaceous sandy clayey silt with occasional nodules of ironstone and siltstone. Inclinometer records show that no movement within slumped material took place within $\mathrm{BH} 1$ and $\mathrm{BH} 7$ during the period of monitoring.

The lithologies present within $\mathrm{BH} 5$, located on the eastern most flow lobe, follow a similar sequence to boreholes 1 and 7; a thin layer of top soil, followed by a series of clay-dominated flow deposits, three rotational slump deposits and in-situ Staithes Sandstone Formation. Flow deposit thickness is one metre thicker in borehole 5 than boreholes 1 and 7 located on the other investigated lobe, the second lobe to the east. Inclinometer records show two active shear planes, between $0.5 \mathrm{~m}$ and 1.0 $\mathrm{m}$ - within flowed material - and between $4.0 \mathrm{~m}$ and $4.5 \mathrm{~m}$ within slump deposits.

\subsection{Soil properties}

\subsubsection{Clay content and mineralogy}

The plasticity index and liquid limit of the unstable formations were determined and results presented in a plasticity plot, Figure 6 . The results show that WMF consistently has a high to very high plasticity with all points plotting below the a-line indicating that the formation behaves in a siltlike manner. Whereas SSF has a lower liquid limit, plasticity index and plasticity compared to WMF, and is attributed to SSF having a higher silt and/or sand content.

Clay mineralogy, determined from XRD analysis of material recovered from $\mathrm{BH}$, is summarised in Table 1. Clay contents vary from more than $50 \%$ to less than $6 \%$, with illite-smectite and kaolinite represented. The sample of the slip surface within SSF - at $5.2 \mathrm{~m}$ - has a higher Illite-Smectite content (26.6\%) compared to other SSF-derived samples. Samples from $4.35 \mathrm{~m}, 5.2 \mathrm{~m}$ and $5.7 \mathrm{~m}$ have a chlorite content of between 3.7 and $7.4 \%$, which could be a result of the slip surface acting as a conduit for clay minerals, transported by groundwater flow or rainfall infiltration. Comparison of the XRD and CEC results (i.e. Figure 5 and Table 1) shows a consistent correspondence between high clay contents and CECs, demonstrating that CEC is a good indicator of clay content at this site.

\subsubsection{Soil Cation Exchange Capacity - resistivity relationships}

By plotting resistivity - determined by soil conductivity probe in the laboratory - of the cored samples versus their cation exchange capacity of 32 samples from various depths throughout BH5 
and $\mathrm{BH} 7$ it is possible to differentiate between the formations present based solely on their electrical properties. Figure 7 presents cored soil resistivity versus CEC in semi-log space and shows the presence of two clustered groups of results. The first cluster of results shows a range of electrical resistivities and CEC values of between 28-115 ohmm and 7-14 meq/100g and corresponds to sand flow deposits, slumped material and in-situ SSF and are represented on the resistivity-CEC plot as red, green and orange points respectively. The second cluster produced resistivities and CEC values of between 8-14 ohmm and 25-30 meq/100g respectively. This cluster is composed of WMF-derived flow deposits as low resistivity and high CEC values are indicative of clay-rich material.

Located between cluster 1 and 2 are five data points which do not clearly belong to either the SSF or WMF clusters, and are attributed to clay rich layers located towards the top of SSF-derived slump deposits. In addition, two data points from clay flow material (BH5, $1.5 \mathrm{~m} \& 2.0 \mathrm{~m}$ ) also plot between the cluster and are attributed to a WMF derived flow deposit with a higher sand content ( $20 \%$ sand) relative to the clay flow cluster ( $\sim 5$ sand).

\subsubsection{Soil resistivity}

Borehole 7 is seen to contain several zones of varying resistivities and good correlation exists between the various lithological and structural units found within the core. A thin layer of top soil exists from the surface to a depth of $0.2 \mathrm{~m}$ with a resistivity of $20 \Omega \mathrm{m}$. The first clay-dominated flow exists between the top soil and $0.7 \mathrm{~m}$ depth, has a core resistivity of $10 \Omega \mathrm{m}$ and CEC value of 25-27 meq/100g. Beyond the first flow deposit are a further three flows which have similar resistivities ranging between $40 \Omega \mathrm{m}$ and $60 \Omega \mathrm{m}$, where the flow deposits are met by an abrupt increase in resistivity at $1.6 \mathrm{~m}$. At this depth the clay-dominated flow deposits give way to sand-dominated flows along with associated resistivity increase to between $70 \Omega \mathrm{m}$ and $120 \Omega \mathrm{m}$. CEC results for this series of sandy flows are consistently lower than those of the clay flows at around $6 \mathrm{meq} / 100 \mathrm{~g}$. The boundary between flow and slump deposits is marked by a decrease in resistivity at $3.0 \mathrm{~m}$ depth from $\sim 100 \Omega \mathrm{m}$ to between 20 and $60 \Omega \mathrm{m}$ and with it comes a distinct change in lithology, as fines content increases from $30 \%$ to $70 \%$. The resistivity of the slump deposits and in-situ SSF extending from $4.0 \mathrm{~m}$ to $7.0 \mathrm{~m}$ (termination of borehole) show a range of values between $30 \Omega \mathrm{m}$ and $100 \Omega \mathrm{m}$. This $3 \mathrm{~m}$ section of the borehole is composed of soil and weak rock layers along with an assortment gravels and sands. Despite the lithological variety shown by the slump and in-situ SSF cation exchange capacity remains constantly between $8-10 \mathrm{meq} / 100 \mathrm{~g}$ within this depth range.

Borehole 5 contains a thicker layer of clay-dominated flow deposits - ascertained through particle size analyses - and core resistivity measurements are persistently low from beyond the top soil 0.3 $\mathrm{m}$ ) to the boundary with the rotational slump deposits at $3.9 \mathrm{~m}$ depth. Resistivity remains at $10 \Omega \mathrm{m}$ from $0.3 \mathrm{~m}$ until $2.7 \mathrm{~m}$ where it steps out for one-metre to $35 \Omega \mathrm{m}$, between $2.7 \mathrm{~m}$ and $3.7 \mathrm{~m}$ depth. Cation exchange capacity measurements within the clay flows between $0.3 \mathrm{~m}$ and $2.8 \mathrm{~m}$ vary between 19 and $30 \mathrm{meq} / 100 \mathrm{~g}$. Between $2.7 \mathrm{~m}$ and $3.7 \mathrm{~m}$ the CEC is between 8 and $10 \mathrm{meq} / 100 \mathrm{~g}$ and coincides with a sand-dominated flow deposit possessing reduced clay content. The lowermost flow deposit and the uppermost slump deposit are located between $3.7 \mathrm{~m}$ and $4.1 \mathrm{~m}$ depth and show a resistivity and CEC of $10-20 \Omega \mathrm{m}$ and $20 \mathrm{meq} / 100 \mathrm{~g}$ respectively.

Slump deposits show an almost consistent resistivity from $4.1 \mathrm{~m}$ to $5.7 \mathrm{~m}$ which marks the contact with in-situ SSF and are between $25 \Omega \mathrm{m}$ and $45 \Omega \mathrm{m}$, a much narrower range when compared to borehole 7. Core resistivity of $I n$-situ SSF gradually increases with depth from $30 \Omega \mathrm{m}$ at $6.0 \mathrm{~m}$ depth 
to $80 \Omega \mathrm{m}$ at $6.5 \mathrm{~m}$. Two high resistivity outliers of over $250 \Omega \mathrm{m}$ exist within in-situ SSF and are attributed to thin layers of weak siltstone. Between $4.1 \mathrm{~m}$ and $6.5 \mathrm{~m}$ the CEC measurement varies consistently between 9 and 14 meq/100g.

Resistivity measurements made on soil cores show a range of values. This is due to the lithological variation within each soil type, which manifests as layers of more or less resistive material in core resistivity measurements. Accumulation and dissipation of soil moisture content also contribute to resistivity variability in subsurface material and varies both spatially and temporally within the subsurface.

\subsection{Volumetric resistivity imaging (3D ERT)}

\subsubsection{Low resolution}

The result of the large-scale ERT surveys of the landslide system is presented in Fig. 8. Three geological formations are present and are distinguished from one another by their relative differences in model resistivity (also see section 4.4.3). High relative resistivities are expressed as warm colours such as browns, oranges and yellows, whereas relatively low resistivities appear blue and green. The low resistivity formation present at the top of the slope (z-axis, $100 \mathrm{~m}$ ) is WMF and has a resistivity of 10-20 $\Omega \mathrm{m}$. Borehole derived measurement of resistivity of the soil core samples recorded a resistivity of between 10 and $20 \Omega \mathrm{m}$ (Fig. 5). Clay-dominated flows can be seen between $0.2 \mathrm{~m}$ and $0.7 \mathrm{~m}$ at $\mathrm{BH} 7$ and $\mathrm{BH} 1$, and $0.3 \mathrm{~m}$ and $2.7 \mathrm{~m}$ at $\mathrm{BH}$. These resistivity values are in agreement with results of ERT surveys, thus confirming the presence and extent of clay-dominated flows - WMF derived - within both the survey and field site. This is the main formation which supplies material to form the flow lobes at Hollin Hill. The higher resistivity SSF is sandwiched between two low resistivity (blue) formations. When compared with WMF and RMF, SSF has a wider range of model resistivities, between 40 and $120 \Omega \mathrm{m}$. Again, borehole derived measurement of resistivity show similarity with ERT survey results as SSF exhibits core sample resistivities ranging between 30 and $100 \Omega m$ (see Fig. 5).

The stepped nature of the boundary between RMF with SSF in Fig. 8 is an artefact of the inversion process and increased sized of model blocks with depth. The more resistive regions of the tomogram are where the SSF crops out at the surface, this occurs towards the base of the slope, at the southern limits of the surveyed area. The uppermost $\sim 4 \mathrm{~m}$ of Staithes Sandstone has relatively high resistivities in the order of $70-120 \Omega \mathrm{m}$, below this layer the resistivity of the formation is lower at around $40 \Omega \mathrm{m}$. This unsaturated and free-draining layer is subjected to seasonal soil moisture content variation as a result of evapotranspiration. Below this more resistive zone the Formation appear to be reasonably homogeneous with respect to electrical resistivity. Finally, placed stratigraphically below SSF is a formation which appears dark blue in colour and is called Redcar Mudstone Formation. RMF, similarly to WMF is a mudrock formation and has a model resistivity of 10-20 $\Omega \mathrm{m}$. All three stratigraphical formations share a similar dip of between $5^{\circ}$ and $10^{\circ}$ to the North as can be seen from the layer boundaries in figure 8 . An annotated cross section - parallel with the $\mathrm{y}$-axis - is shown in Fig. 9 and has the interpreted core log of $\mathrm{BH} 7$ superimposed to aid the positioning of the three main rotational slip surfaces. Rotational slump shear surfaces were identified during core logging, however no geomorphological evidence, nor resistivity contrast exists within ERT survey images to suggest the exact orientation, length or form of these surfaces. The 
dearth of geomorphological evidence is due to the degradation of both the slumped SSF as a flow and the subsequent flowing of WMF up and over the SSF slumped material.

Rotational slip surfaces within WMF were matched with geomorphologic features picked out from LiDAR information and walkover survey. The material that composed the back scarp or slump block of that slump has since been activated, incorporated into a flow and deposited further down the slope. The boundary between the flow deposit of WMF - shown as a low resistivity (blue) mantle with SSF-composed rotational slumps and in-situ SSF is clearly marked by a change in resistivity from 10-20 $\Omega \mathrm{m}$ (WMF) to 50-65 ohmm (SSF) and also correlates well with the interpreted borehole log of BH7. Flow deposits appear to thin in a southerly direction and show a maximum thickness of $\sim 5-6 \mathrm{~m}$. Two flow lobes can be seen in Figure 8 and form the two pointed features at the sides of the image as the unstable WMF flows down the slope over the underlying SSF.

The model cell versus resistivity plot (Fig. 8, right) is used to illustrate the range of resistivity values for each lithological formation and acts as a guide - during ground model development - when applying ERT results to inform the ground model about spatial distribution of lithologies.

\subsubsection{High resolution}

Results of the high-resolution survey of the flow region are shown in Figure 10 along with the positions of $\mathrm{BH} 1$ and $\mathrm{BH} 7$. Figure 10a shows the flow region at a higher resolution to the large-scale survey presented in Figures 8 and 9, thus permitting the observation of additional subsurface features in the near-surface. Much of the surface is dominated by the blue coloured, lower resistivity unit which is composed of clay-dominated flow deposits of WMF. These flow deposits appear thinner in the high resolution survey and have a maximum thickness of $3 \mathrm{~m}$. In order to make the low-resistivity flow deposits more visible Figure 10b shows the blue flow deposits in $100 \%$ opacity but with the underlying units which possess higher resistivities at $50 \%$ opacity. From this figure the spatial distribution of the clay-rich, low resistivity flow deposit is clear, it thins towards its periphery like a thin veneer over the underlying formation. This is in agreement with borehole data which suggests that clay-dominated flows exist from the surface to a depth of $0.5 \mathrm{~m}$ and $0.8 \mathrm{~m}$ at BH7 and $\mathrm{BH} 1$ respectively. In the north of the survey area the clay-dominated, blue coloured, flow deposits appear thicker than to the south of the area. This thickening of the blue unit is attributed to stacking of flow deposits over one another as the landslide system evolved. Directly below the claydominated flow deposits is a more resistive, tabular shaped unit with an electrical resistivity of between 80-120 $\Omega \mathrm{m}$. This silty sand unit is interpreted as a flow deposit which has experienced weathering-induced alteration. Boreholes 1 and 7 show that the lithology of the sand flow deposit is different to that seen elsewhere at the site, as the flows contain a greater sand content than WMF, in-situ SSF and slumped SSF. This alteration could be attributed to weathering processes or mechanical reworking while in flow as the finer material has been preferentially removed from the soil. The sand content of the sand flow is between $50-70 \%$ yet the rest of the formations present at the hill slope contain a relatively low proportion of sand. It is therefore uncertain as to provenance of this sand flow however the weathering of a WMF-composed flow seems the most credible.

Fig. 11 is a profile through the 3D volumetric image of model resistivity (Fig. 9) and is superimposed with interpreted borehole logs 1 and 7. Both 2D profiles offer good correlation with core logged data as all lithological and structural boundaries are identifiable and well constrained. Figure 10 identifies a small resistivity difference between the sand flow and the rotational slump deposits 
which are composed of SSF. The resistivity is seen to reduce across the boundary between the flow and slump deposits from $80 \Omega m$ to $50 \Omega m$.

\section{Ground model development}

The ground model of Hollin Hill was generated through the merging of results of many investigative methods and is presented as Figure 12. This section aims to provide a summary of the contribution that each method provided to the process of ground model formulation.

Surface characterisation was performed through the interpretation of visualised airborne LiDAR remote sensing data. Remote sensing data permitted the interpretation of surface morphology breaks in slope - and as a result identification (and location) of landslide type, such as the back scarp and back-rotated blocks indicative of rotational slumping. Visualisation of airborne LiDAR and production of geomorphology map allowed the spatial distribution of landslides to be determined, for example, a series of rotational slumps towards the top of the slope giving way to a number of flow deposits in the mid-slope region. By combining airborne LiDAR with aerial photography the resulting DTM can be used to identify which areas of the landslide are most recently active by looking for surface features such as partially vegetated slopes/areas and abrupt or smoothed breaks in slope.

Low resolution ERT determines the overall structure of the hill slope - at the formational scale - from beyond the back scarp to the relict flow deposits nearing the base of the slope. The low resolution ERT survey picked out three lithological formations present at the field site (WMF, SSF and RMF), identified the nature of the flow deposits positioned over SSF and determined the regional dip of the formations. The low resolution ERT is very much a reconnaissance survey, used to gain information quickly over a large area.

High resolution ERT was performed to gain more information about active flow deposits and in particular their internal structure and lateral persistence. High resolution surveying identified the resistivity contrasts which exist between flow deposits as a result of lithological variation. The blue, low resistivity uppermost flow deposits in contrast with deeper, higher resistivity flows. Core logging and index testing of boreholes performed at the field site shed further light on the reasons behind resistivity variation both between flow deposits and between lithological formations represented. ERT permits the interpolation of interpreted borehole information which can aid determining the landslide structure laterally.

Core logs were interpreted on the basis of mass movement type, so whether the soil cores were flow or slump deposits or in-situ material. The task of differentiating between flow deposits and slump deposits required identification of features associated with each deposit type, for example rotated bedding planes and presence of rip-up clasts is indicate of slumping. Slip surfaces associated with flow deposits were identified as thin $(\sim 5 \mathrm{~mm})$ bands of light brown clay between layers of highly disturbed dark brownish grey silty, sandy clay or slity sand.

Analysis of core soil samples allowed similarities to be drawn between core samples and ERT surveys. For example, core resistivity measurements can be used as a confirmatory tool when interpreting ERT surveys. In order to differentiate between clay and sand flow deposits in the high resolution ERT survey core resistivity measurements were utilised. Core resistivity measurements 
were then related to particle size analyses, the resistivity variation could then be explained in terms of lithology. CEC versus core resistivity plot can inform about potential similarities in resistivities between lithological formations. In our example differentiating between sand flow, slump and in-situ SSF could be problematic and as a result any interpretation took this into account. For this reason the differentiated between in-situ SSF and slumped SSF was impossible and attributed to there being little to no lithological - and therefore electrical property - variation between the two. XRD results also indicate the mineralogical similarities between slumped and in-situ SSF, and dissimilarities with clay and sand dominated flows of WMF.

Implementation of peg displacement results along with ERT surveys and geomorphology studies made it possible to define active landslide regions, types of movement (flow or slump) and rate of displacement. With the addition of inclinometer results the active shear surfaces were identified and incorporated into the ground model.

The concept and methodology of ground model development as outlined by Fookes, 1997 was followed - where appropriate - and tried to inform about all the elements of a ground model; Rock formation and modification processes. Fookes, 1997 outlines that geophysical data must be thoughtfully interpreted and used to improve and refine a developing ground model. In our case, geophysical data complemented the earliest versions of Hollin Hill ground model which were based solely on intrusive information (borehole logs and inclinometer data).

\section{Conclusions}

Geoelectrical methods such as ERT can be usefully applied to landslide investigations where ground truth information is provided and where several lithological formations of contrasting resistivities exist within the area of interest. The investigation presented here informed to a high level of detail about subsurface conditions present within the hill slope by drawing upon many complementary information streams. Where one data set lacked the ability or resolution to inform about a feature or property another could be used to provide such information, an example being the inability of the large-scale ERT to differentiate between slumped and in-situ SSF, instead the positions of the slump shear surfaces in SSF were identified in core logs.

A detailed ground model was developed based on additional high resolution ERT information, remote sensing datasets and thorough interpretation of results from core logging, geotechnical testing and laboratory analysis of core samples. An integrated approach for ground model development, which takes into account both subsurface and surface investigative methods, is shown to improve the conclusions that can be drawn from a given site investigation. This is achieved by calibration of the geophysical results with direct physical property measurements of materials taken from the landslide and its environs. In particular, the use of 3D ERT at different spatial resolutions provides a means of volumetrically characterising the subsurface expression of both site scale (tens of metres) geological structure, and finer (metre to sub-metre) scale earth-flow related structures, which were not effectively revealed by either the 1D information derived from discrete intrusive sampling, or the 2D surface data provided by remote sensing.

A key factor to be considered when designing a resistivity survey in the context of landslide investigation is the electrode spacing, as this has a profound effect on the resolution of the images returned. Resistivity images and profiles must be of a sufficient resolution and quality to permit the 
identification of the features of interest, in our case the individual flow deposits, which were only detectable at the high-resolution afforded by closer electrode spacings.

\section{Acknowledgments}

We wish to convey our sincerest gratitude to Mr. And Mrs. Gibson (the landowners) for their involvement and cooperation throughout. This work was funded by the Natural Environment Research Council - NERC (grant award NE/I1527988/1) and the University of Leeds. This paper is published with the permission of the Executive Director of the British Geological Survey (NERC) and the University of Leeds.

\section{References}

Baldo M, Bicocchi C, Chiocchini U, Giordan D, Lollino G (2009) LIDAR monitoring of mass wasting processes: The Radicofani landslide, Province of Siena, Central Italy. Geomorphology 105 (3):193-201

Bichler A, Bobrowsky P, Best M, Douma M, Hunter J, Calvert T, Burns R (2004) Three-dimensional mapping of a landslide using a multi-geophysical approach: the Quesnel Forks landslide. Landslides (1):29-40. doi:10.1007/s10346-003-0008-7

Chambers JE, Wilkinson PB, Kuras O, Ford JR, Gunn DA, Meldrum PI, Pennington CVL, Weller AL, Hobbs PRN, Ogilvy RD (2011) Three-dimensional geophysical anatomy of an active landslide in Lias Group mudrocks, Cleveland Basin, UK. Geomorphology 125 (4):472-484. doi:10.1016/j.geomorph.2010.09.017

Colangelo G, Lapenna, V., Loperte, A., Perrone, A., Telesca, L. (2008) 2D electrical resistivity tomographies for investigating recent activation landslides in Basilicata Region (Southern Italy). Annals of Geophysics:275-285

Colesanti C, Wasowski J (2006) Investigating landslides with space-borne Synthetic Aperture Radar (SAR) interferometry. Engineering Geology 88 (3):173-199

Cruden DM, Varnes, D.J. (1996) Landslide types and processes. Landslides, Investigation and Mitigation. Special Report 247, Special Report 247 edn. Turner, A.K., Schuster, R.L., Washington, DC

Dahlin, T., Zhou, B., 2004. A numerical comparison of 2D resistivity imaging with 10 electrode arrays. Geophys. Prospect., 52(5), 379-398.

de Bari C, Lapenna V, Perrone A, Puglisi C, Sdao F (2011) Digital photogrammetric analysis and electrical resistivity tomography for investigating the Picerno landslide (Basilicata region, southern Italy). Geomorphology 133 (1):34-46

Dewitte O, Jasselette JC, Cornet Y, Van Den Eeckhaut M, Collignon A, Poesen J, Demoulin A (2008) Tracking landslide displacements by multi-temporal DTMs: A combined aerial stereophotogrammetric and LIDAR approach in western Belgium. Engineering Geology 99 (1):11-22

Di Maio R, Piegari E (2011) Water storage mapping of pyroclastic covers through electrical resistivity measurements. Journal of Applied Geophysics 75 (2): 196-202 doi:10.1016/j.jappgeo.2011.07.009. 
Di Maio R, Piegari E (2012) A study of the stability analysis of pyroclastic covers based on electrical resistivity measurements. Journal of Geophysics and Engineering 9 (2):191

Fookes PG (1997) Geology for Engineers: the Geological Model, Prediction and Performance. Quarterly Journal of Engineering Geology and Hydrogeology 30 (4):293-424. doi:10.1144/gsl.qjeg.1997.030.p4.02

Ford, J.R., In press. Geological Map of the High Stittenham Area (Sheet SE66NE). British Geological Survey, Nottingham, UK.

Godio A, Strobbia C, De Bacco G (2006) Geophysical characterisation of a rockslide in an alpine region. Engineering Geology 83 (1-3):273-286. doi:10.1016/j.enggeo.2005.06.034

Griffiths J, Stokes M, Stead D \& Giles D (2012) Landscape evolution and engineering geology: results from IAEG Commission 22. Bulletin of Engineering Geology and the Environment, 71, 605-636. doi: 10.1007/s10064-012-0434-7

Head KH (2006) Manual of Soil Laboratory Testing: Soil classification and compaction tests. Whittles,

Heincke B, Günther T, Dalsegg E, Rønning JS, Ganerød GV, Elvebakk H (2010) Combined threedimensional electric and seismic tomography study on the Åknes rockslide in western Norway. Journal of Applied Geophysics 70 (4):292-306

Jaboyedoff M, Oppikofer T, Abellán A, Derron M-H, Loye A, Metzger R, Pedrazzini A (2012) Use of LIDAR in landslide investigations: a review. Natural Hazards 61 (1):5-28. doi:10.1007/s11069-0109634-2

Jomard H, Lebourg T, Binet S, Tric E, Hernandez M (2007) Characterization of an internal slope movement structure by hydrogeophysical surveying. Terra Nova 19 (1):48-57. doi:10.1111/j.13653121.2006.00712.x

Jongmans D, Garambois S (2007) Geophysical investigation of landslides: A review. Bulletin de la Societe Geologique de France 178 (2):101-112

Jordan C, Bateson L, Bow J, Newell A, Napier B, Sabine RJ, British Geological Survey, Tethys Petroleum (2009) GeovisionaryTM software for 3D visualisation and petroleum exploration in southern Tajikistan. Paper presented at the RSPSoc 2009 : New Dimensions in Earth Observation, Leicester, UK.

Lapenna V, Lorenzo P, Perrone A, Piscitelli S, Sdao F, Rizzo E (2003) High-resolution geoelectrical tomographies in the study of Giarrossa landslide (southern Italy). Bulletin of Engineering Geology and the Environment 62 (3):259-268. doi:10.1007/s10064-002-0184-z

Lebourg T, Binet S, Tric E, Jomard H, El Bedoui S (2005) Geophysical survey to estimate the 3D sliding surface and the $4 \mathrm{D}$ evolution of the water pressure on part of a deep seated landslide. Terra Nova 17 (5):399-406. doi:10.1111/j.1365-3121.2005.00623.x

McDowell P, Barker RD, Butcher A, Culshaw M, Jackson P, McCann D, Skipp B, Matthews S, Arthur J (2002) Geophysics in engineering investigations. Ciria 
Perrone A, lannuzzi A, Lapenna V, Lorenzo P, Piscitelli S, Rizzo E, Sdao F (2004) High-resolution electrical imaging of the Varco d'Izzo earthflow (southern Italy). Journal of Applied Geophysics 56 (1):17-29. doi:10.1016/j.jappgeo.2004.03.004

Perrone A, Zeni G, Piscitelli S, Pepe A, Loperte A, Lapenna V, Lanari R (2006) Joint analysis of SAR interferometry and electrical resistivity tomography surveys for investigating ground deformation: the case-study of Satriano di Lucania (Potenza, Italy). Engineering Geology 88 (3-4):260-273. doi:10.1016/j.enggeo.2006.09.016

Powell J (1984) Lithostratigraphical nomenclature of the Lias Group in the Yorkshire Basin. In: Proceedings of the Yorkshire Geological and Polytechnic Society.Geological Society of London, 45:5157. doi:10.1144/pygs.45.1-2.51

Rawson PF, Wright, J.K. (1995) Field Geology of the British Jurassic. In: Taylor PD (ed) Jurassic of the Cleveland basin, North Yorkshire. Geological Society of London, London, UK, pp 173-208

Revil A, Glover, P. W. J. (1998) Nature of surface electrical conductivity in natural sands, sandstones, and clays. Geophys Res Lett 25 (5):691-694. doi:10.1029/98gl00296

Reynolds, J. (2011). An introduction to applied and environmental geophysics. John Wiley \& Sons, Ltd.

Sass O, Bell R, Glade T (2008) Comparison of GPR, 2D-resistivity and traditional techniques for the subsurface exploration of the Öschingen landslide, Swabian Alb (Germany). Geomorphology 93 (12):89-103

Schmutz M, Guérin R, Andrieux P, Maquaire O (2009) Determination of the 3D structure of an earthflow by geophysical methods. The case of Super Sauze, in the French southern Alps. Journal of Applied Geophysics 68 (4):500-507

Telford WM, Geldart LP, Sheriff RE (1990) Applied Geophysics. Cambridge University Press, Topp G, Davis J, Annan AP (1980) Electromagnetic determination of soil water content: Measurements in coaxial transmission lines. Water Resour Res 16 (3):574-582

Udphuay S, Günther T, Everett ME, Warden RR, Briaud J-L (2011) Three-dimensional resistivity tomography in extreme coastal terrain amidst dense cultural signals: application to cliff stability assessment at the historic D-Day site. Geophysical Journal International 185 (1):201-220. doi:10.1111/j.1365-246X.2010.04915.x

Wilkinson, P., Loke, MH, Meldrum, PI, Chambers, JE, Kuras, O, Gunn, DA, and Ogilvy, RD., 2012. Practical aspects of applied optimised survey design for Electrical Resistivity Tomography. Geophysical Journal International, 189(1), 428-440. 
Fig. 1. Geological map of the study area, and inset large scale map. Geological mapping, BGS (C) NERC. Contains Ordnance Survey data (c) Crown Copyright and database rights 2013.

Fig. 2. Plan view of study site, annotated with lithological boundaries (dashed white lines), positions of pegs (yellow points), borehole locations (light blue points) and areas of high- and low-resolution ERT surveys (low-res array: red rectangle, high-res array: purple rectangle). Orange and lilac lines indicate positions of interpreted profiles presented as Figures $9 \& 11$ respectively. Inset left shows the position and number reference of GPS pegs. Coordinate system is British National Grid (BNG). Illustration of study site based upon an aerial photograph (C) UKP/Getmapping Licence No. UKP2006/01

Fig. 3. Displacements of seven pegs at field site by repeat measurement by RTK-GPS.

Fig. 4. Geomorphology map of the field site produced from an airborne LiDAR dataset, visualised using GeoVisionary software and presented using ArcGIS10. The top of the slope is towards the north of the map, with the base towards the south, coordinate system used is BNG.

Fig. 5. Interpreted core logs including particle size analyses, moisture content, cation exchange capacity, core resistivity and inclinometer data of boreholes: $\mathrm{BH} 1, \mathrm{BH} 5$ and $\mathrm{BH} 7$. The cores, core logs and photos were analysed and lithological layers were classified into one of four types: top soil, flow deposit, slump deposit or in-situ SSF.

Fig. 6. Plot of Atterberg Limits results for soil samples from $\mathrm{BH} 7$ and $\mathrm{BH}$. A-line plot presents results as plasticity index versus liquid limit and shows the plasticity of soil samples.

Fig. 7. Plot of core resistivity measurements versus cation exchange capacity of core samples from borehole $\mathrm{BH} 5$ and $\mathrm{BH} 7$. Coloured points represent different structural zones from the interpreted borehole logs (Fig. 5).

Fig. 8. 3D volumetric image of resistivity from the low-resolution ERT survey (red rectangle on basemap, Fig. 3.) (left). Geological boundaries are marked with a white dashed line and formation names with white text. Plot of height of model cell (z-axis) versus resistivity for low-resolution ERT survey and shows distribution of lithological formations at Hollin Hill (right).

Fig. 9. 2D ERT profile extracted from low-resolution 3D ERT survey. Profile runs parallel ( approximately north-south) with y-axis and includes BH7. Rotational shear surfaces are represented by black dashed lines. Orientation and location of 2D ERT profile is indicated by an orange profile line on the basemap, Fig.2.

Fig. 10. 3D volumetric image of resistivity from the high-resolution ERT survey (purple rectangle on the basemap, Fig.2.) A white dashed line indicates the boundary between WMF and SSF and two red points indicate borehole locations. Fig.10a displays resistivity model of earthflow region at $100 \%$ opacity, Fig.10b displays the higher resistivity zone at $40 \%$ opacity and maintains the lower resistivity earthflow at $100 \%$ opacity. N.B. Low resistivity features at the base of the image are likely to be artefacts of the inversion process associated with regions of very low sensitivity (and hence resolution). 
Fig. 11. Annotated profile through high-resolution ERT survey whose location is indicated by a lilac profile line on basemap (Fig.2.) White lines represent flow surfaces with arrows indicating relative flow direction. The interpreted borehole log of BH7 shows structure of landslide system by landslide deposit type.

Fig. 12. Ground model of the Hollin Hill study site based on geophysical, geomorphological and geotechnical investigations.

Table 1. Results of X-ray diffraction analysis of six soil samples from $\mathrm{BH} 7$ which show the mineralogical composition of geological formation at the study site. 


\section{Figure}

Click here to download Figure: Fig1.eps

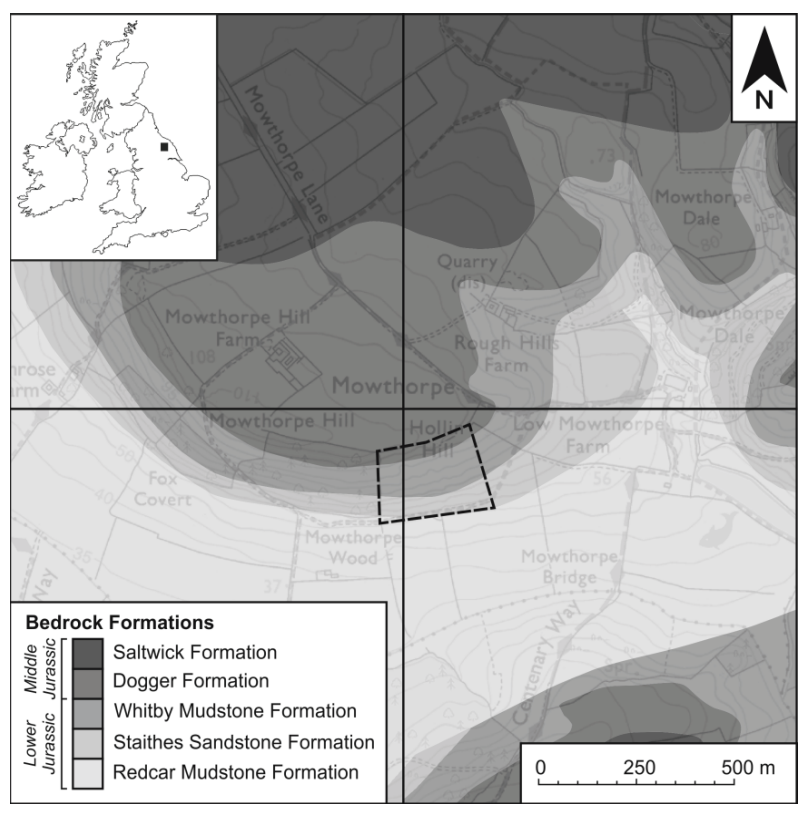




\section{Figure}

Click here to download Figure: Fig2.eps

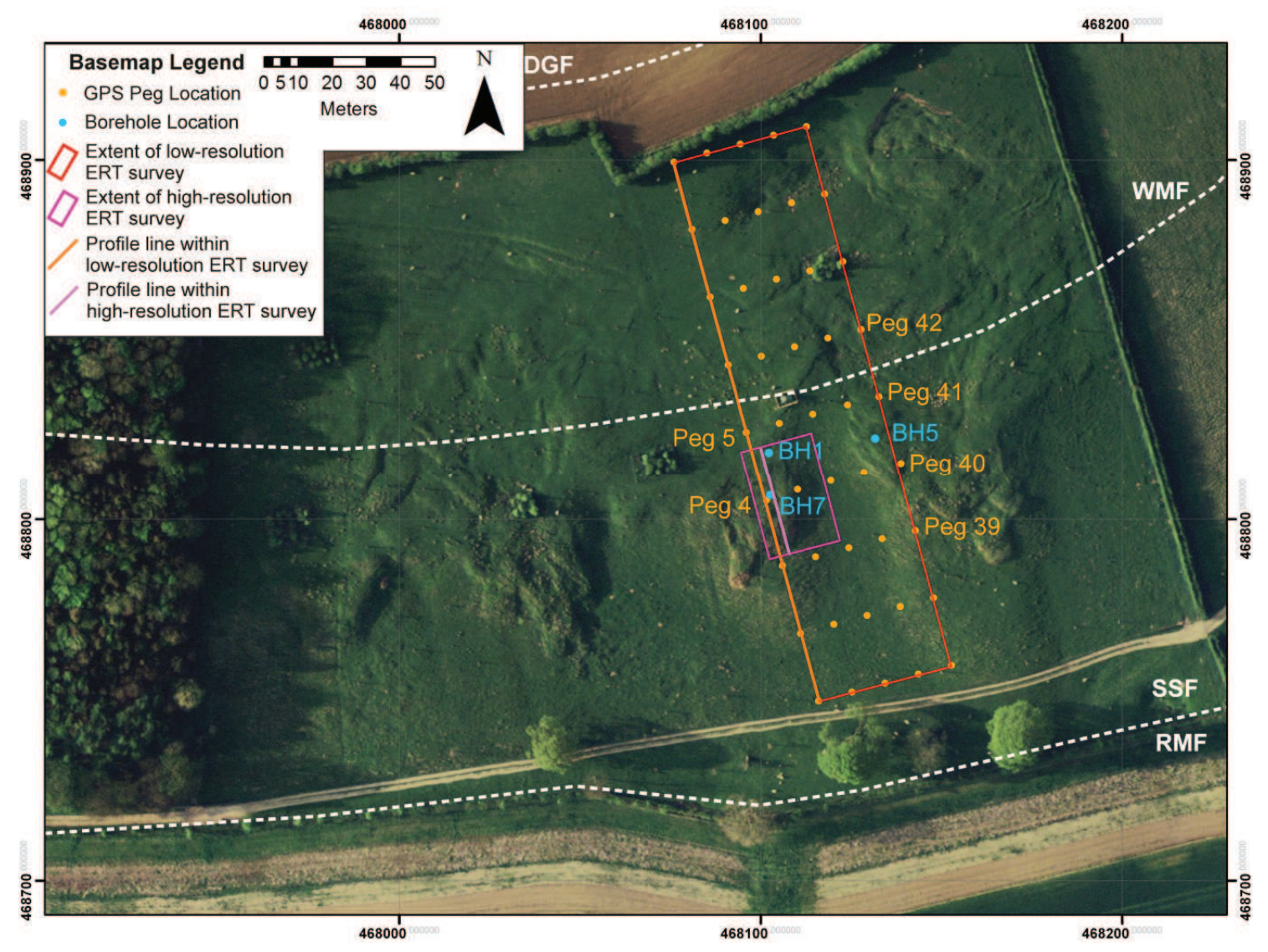




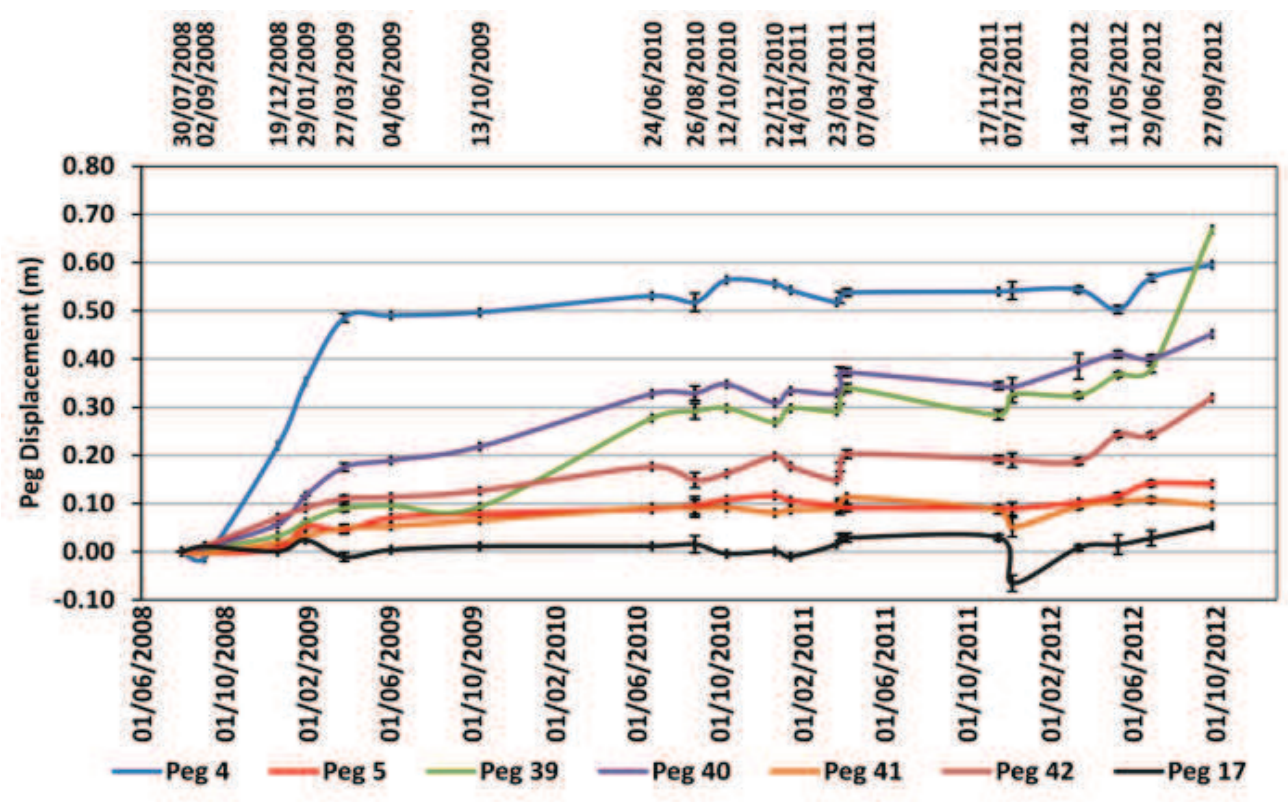




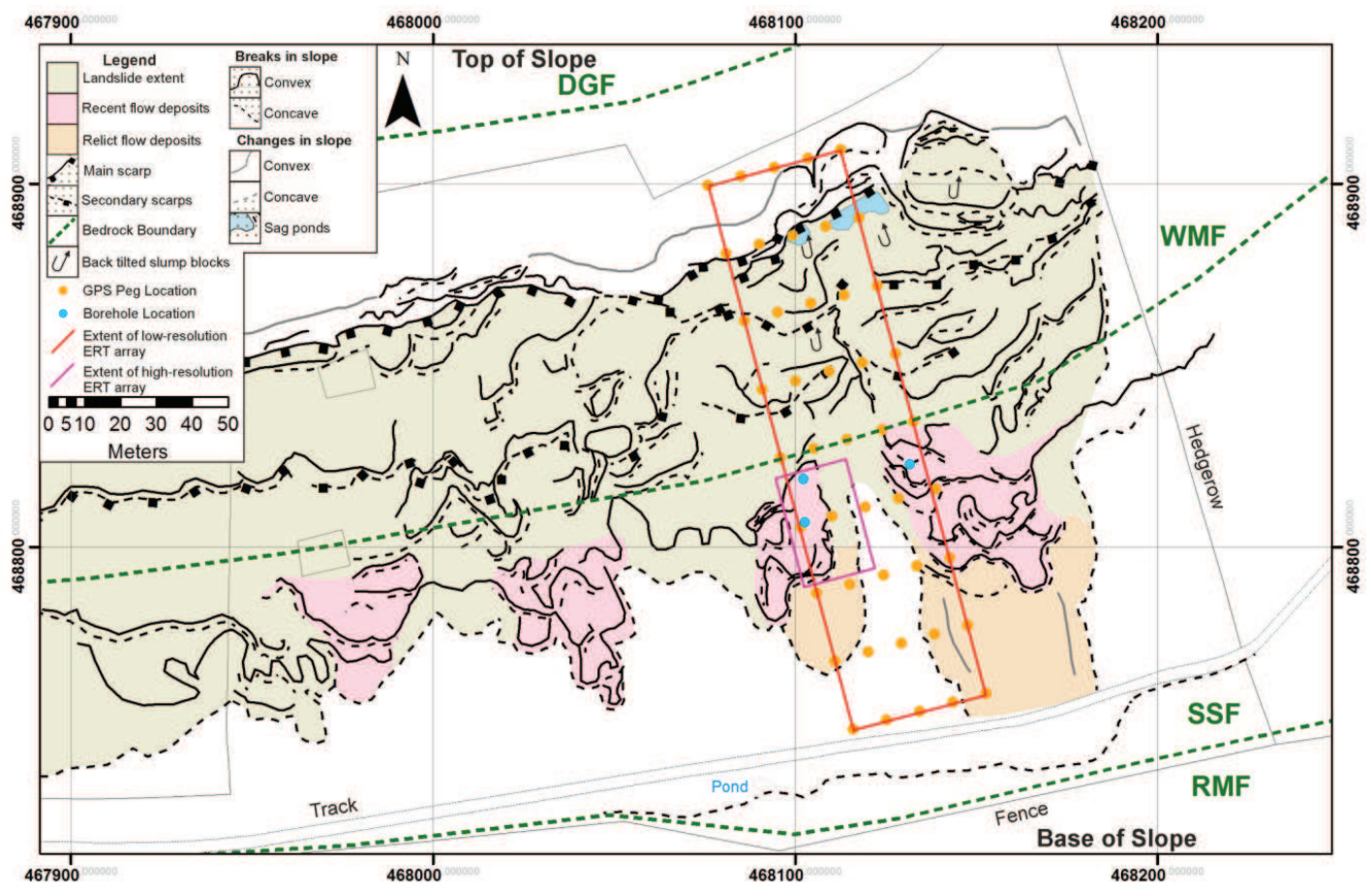




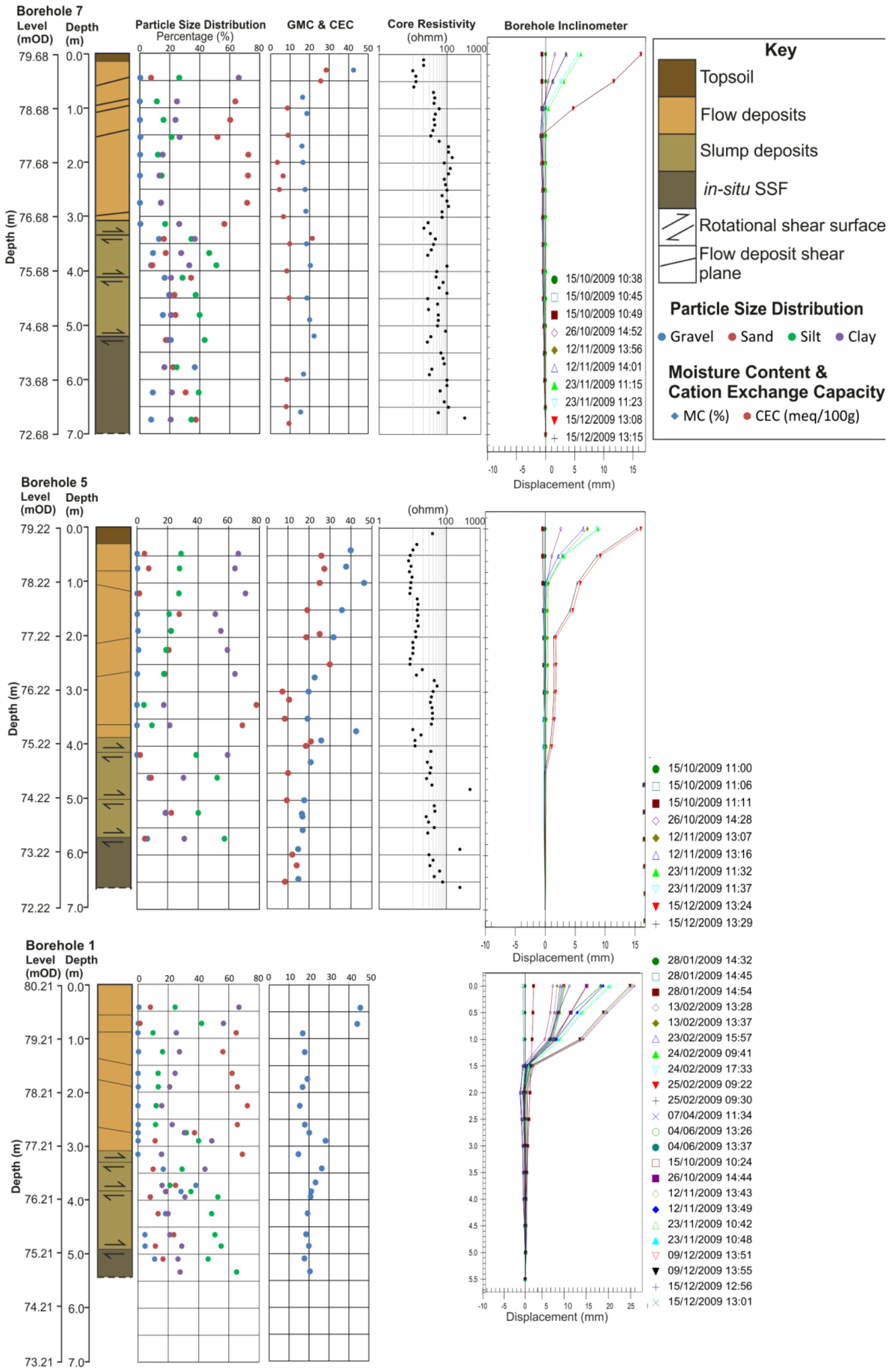


Figure

Click here to download Figure: Fig6.docx

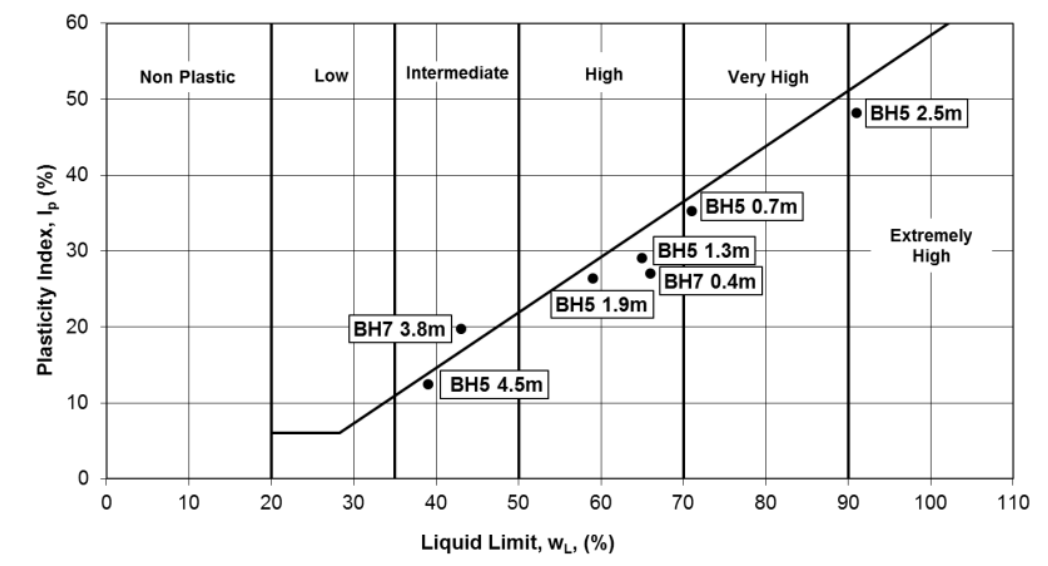


Figure
Click here to download Figure: Fig7.eps

Figure
Click here to download Figure: Fig7.eps
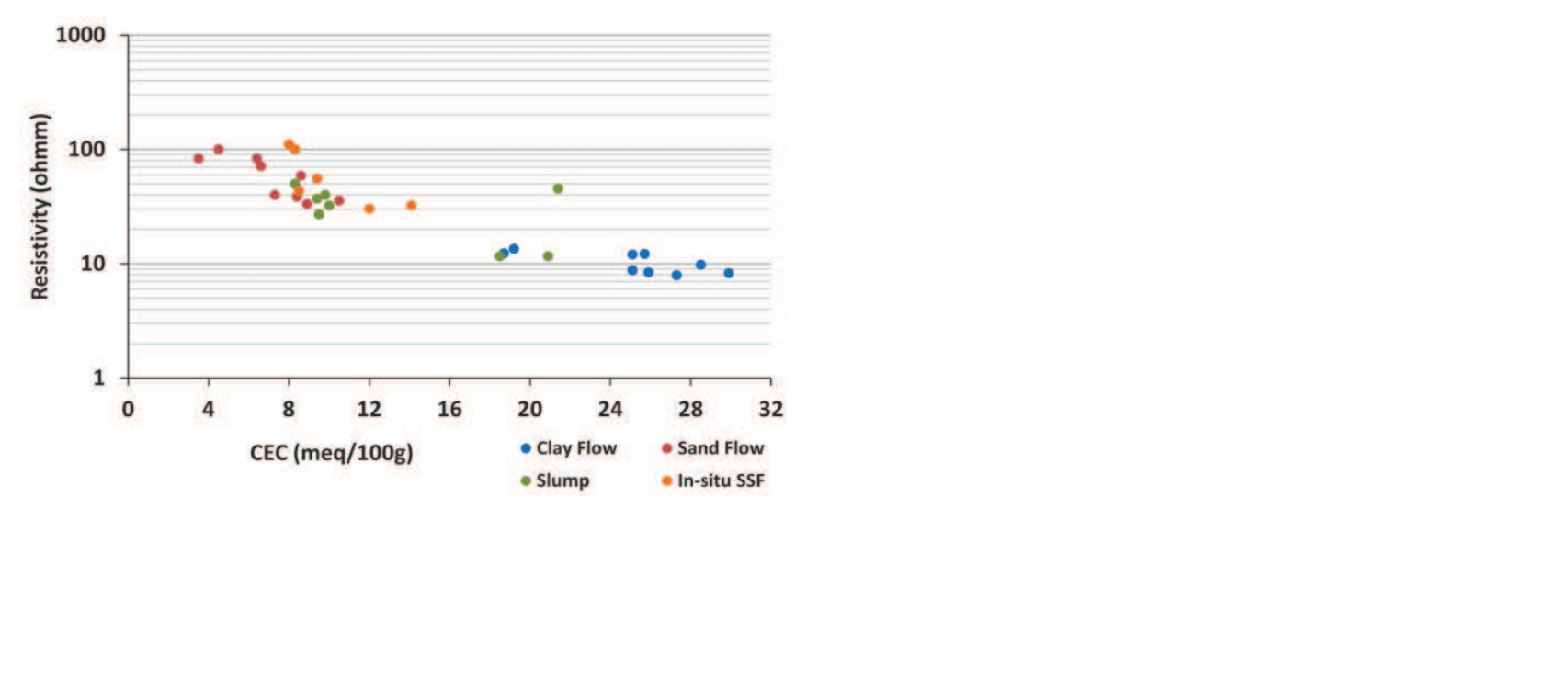

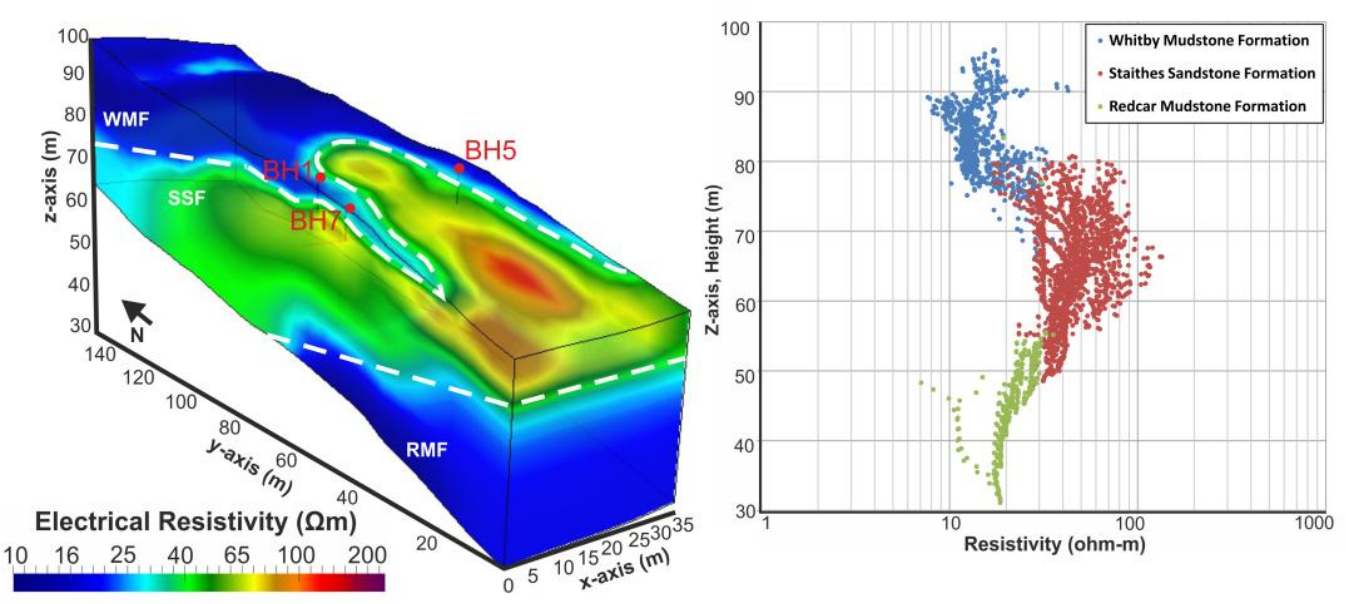
Click here to download Figure: Fig9.docx

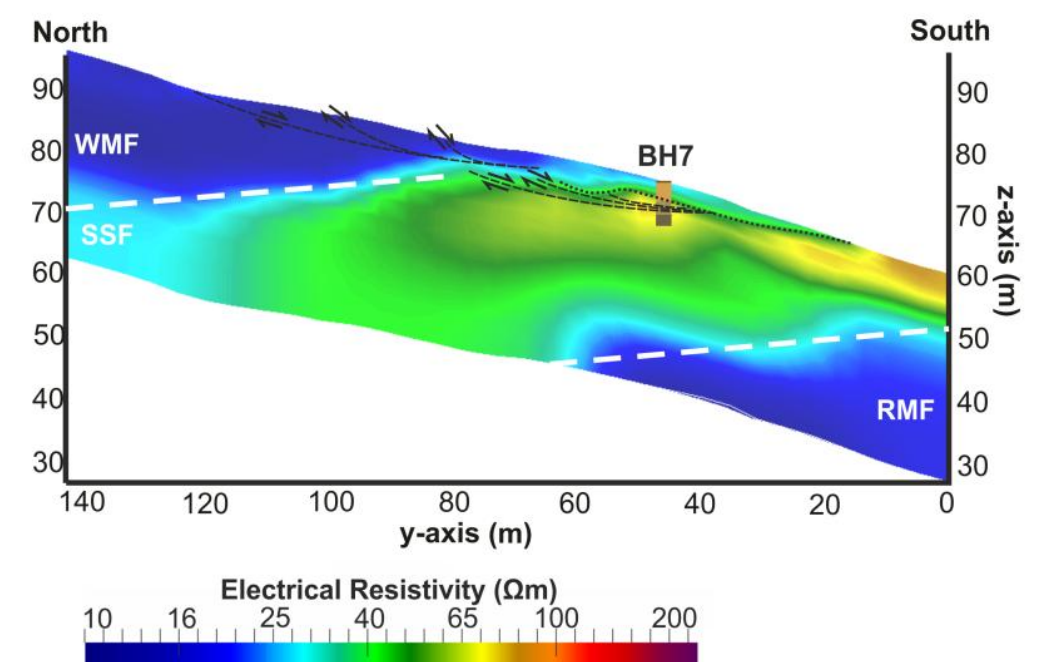

$10 \quad 16 \quad$ Electrical Resistivity $(\Omega \mathrm{m})$

$++16+25 \quad 40 \quad 65,100,200$

(1) 


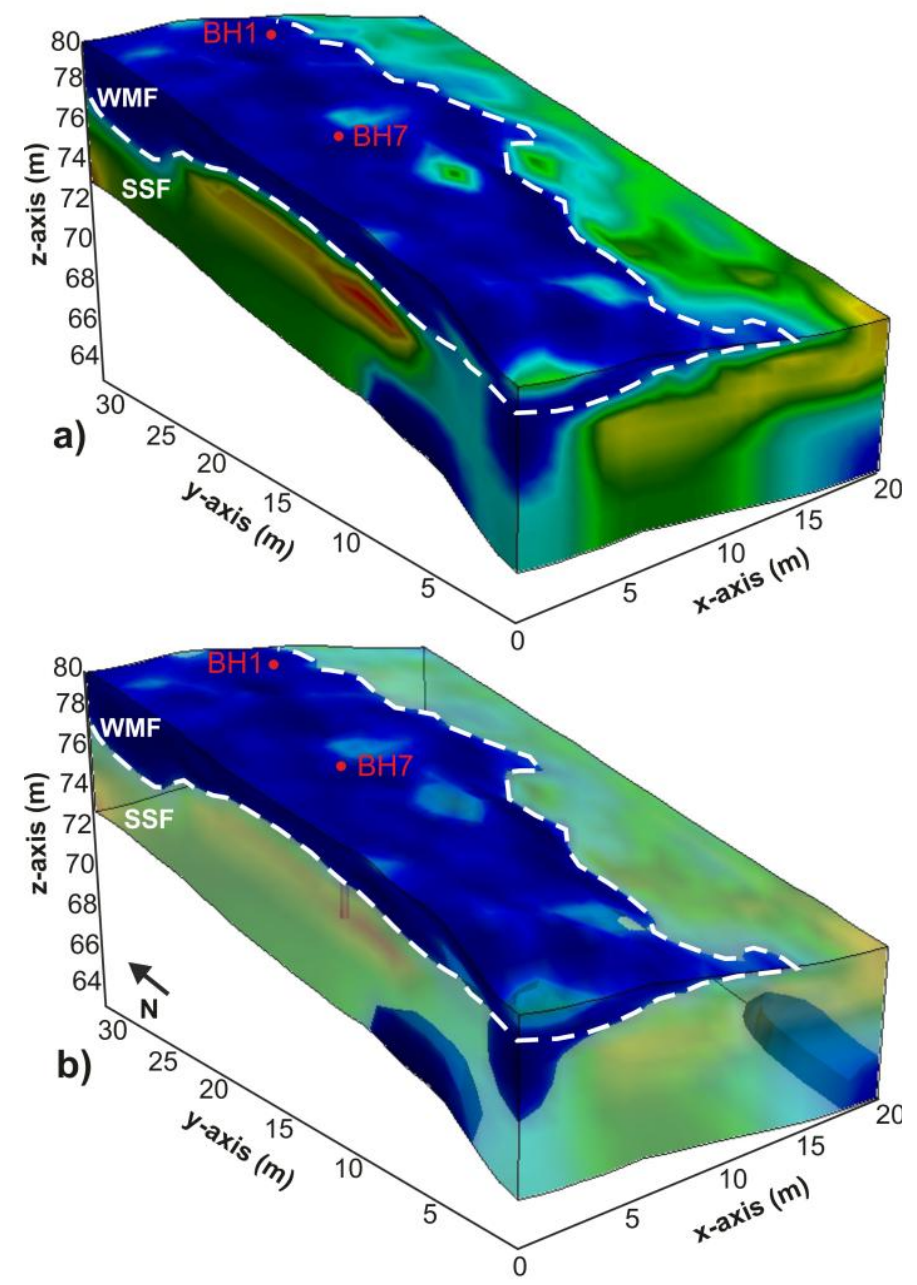

\begin{tabular}{llccc}
\multicolumn{1}{c}{ Electrical Resistivity $(\Omega \mathrm{m})$} \\
$10 \quad 16$ & 25 & 40 & 65 & 100
\end{tabular} 

very little evidence of landslide activity, potentialy due to removal of evidence by farm practikes.
Arable farmland:
Active flow deposits of WMF:

inac tive slumps of SSE:

intermediste plasticity high to very high plasticity

(evident only in drilled cores)

KEY

Whitby Mudstone Formation

Stalthes Sandstone Formation

Redcar Mudstone formation

compired

removal of clays by infiltrating raintall
Crown cracks Sag ponds and associated
tall reed grass

\section{Mature woodiand:} trees uprooted and deformed

by llump movemert

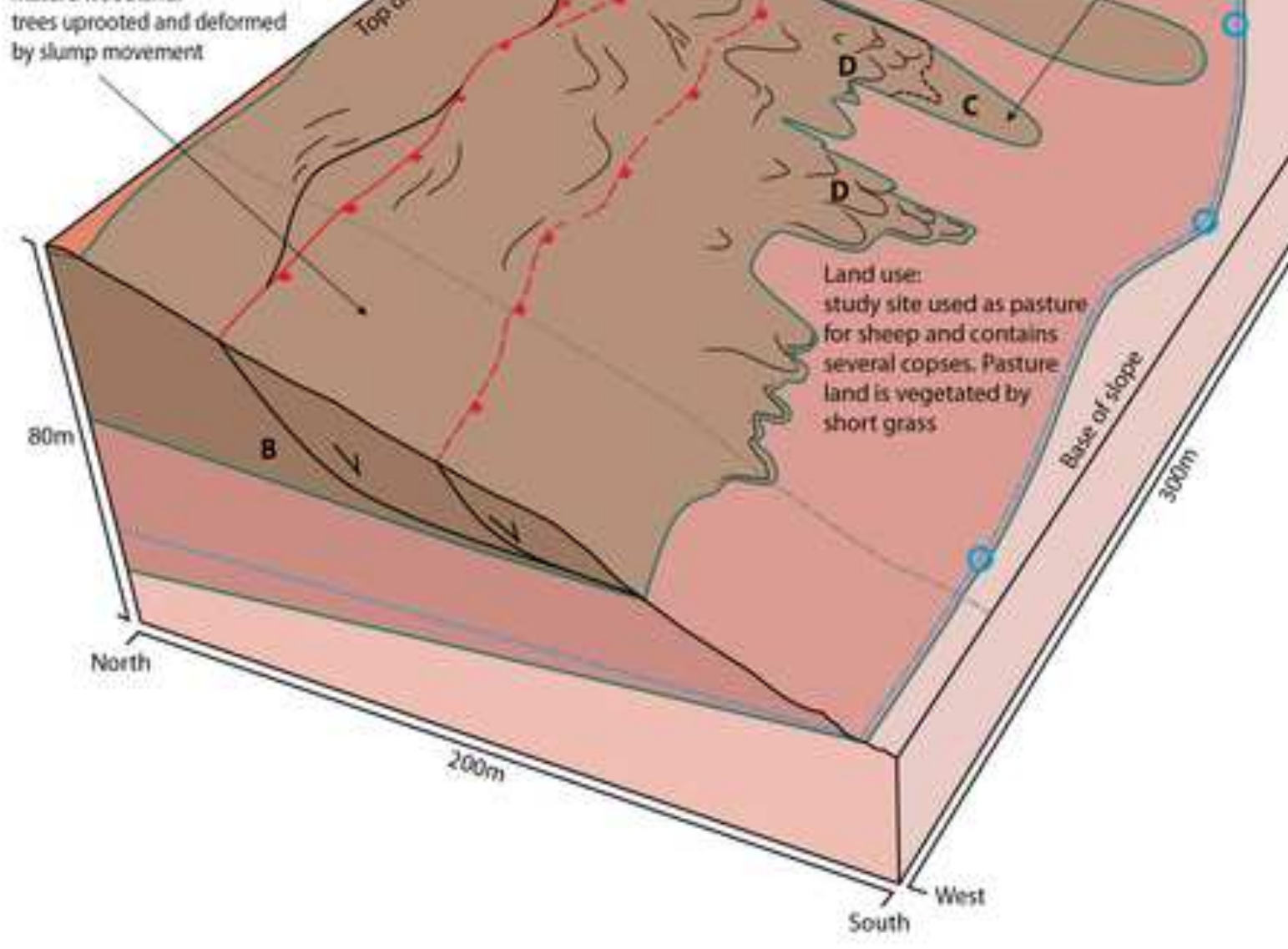

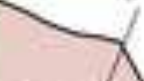

\section{Hedgerow \\ .

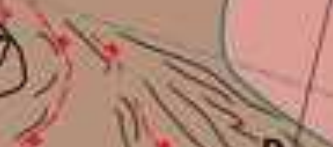

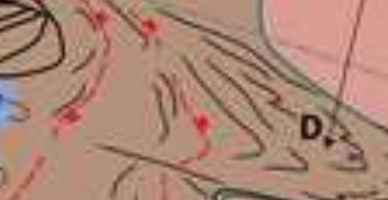

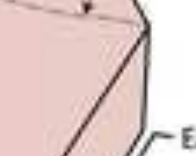

\section{Geological boundary}

- Main scarp

In- Secondary scarp

\section{Surface morphology feature}

Boundary between recent and ancient flow deposits

Water table linferred from

f Back-tilted slump block

Spring (seasonally active) seasonal spring positions

\section{Landslide Characterisation:}

Landslide system is interpeeted as a complex, composite, successive artheside earth flow.

A) Inaxtive, earth-slides within SSF (hidden beneath WMF flow deposits, evident in drilled cores?

8) Inactive, retrogressive earth-slides within WMF, occurring as a series of $\sim 3$ slump blocks. Secondary scarps display throws of between $1.2 \mathrm{~m}$ and are predominintly orientated east-west

C) Inactive, relict, debris-flows of WMF which appear lobate and well degraded

D) Active, earth-flows ate very slow and composed of stumped WMF. activate during periods of prolonged rainfall

E) Active, shallow, retrogresshe earth-shides occur at the backscarp with slump blocks depositing onto the landslide main body.

Landsfides to the West of site sppear currently less active. Potentisliy due to upsake of moisture in subsurface by mature woodland

Landslides to the East of site appear to be curnently most active and could be attributed to back-rotated block permitting sag ponds to form and water to inflitrate 
Table

Click here to download Table: Table1.eps

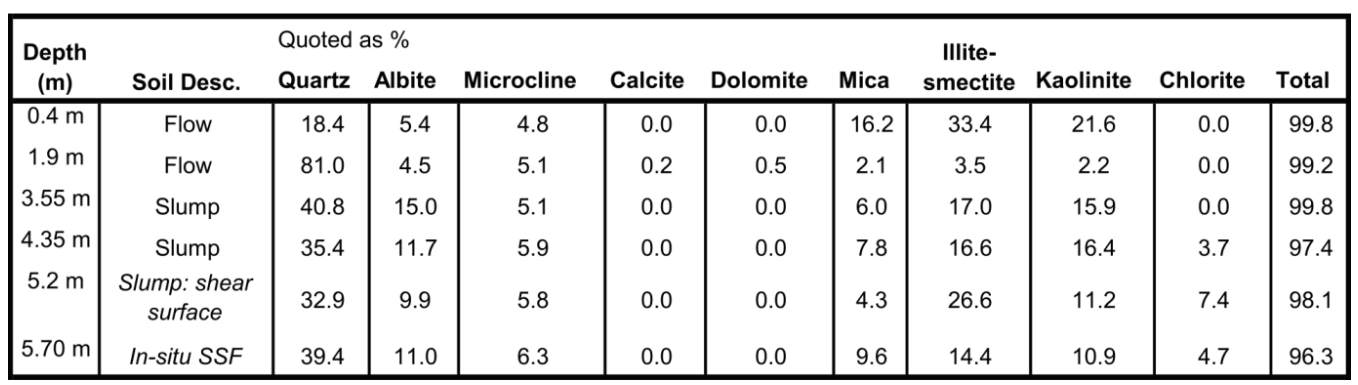




\section{Comments to Reviewers (Manuscript LASL-622)}

I thank you both for your thoughtful commentary.

\section{Reviewer \#1}

1) "Shortening by 2 pages"

I have tidied and shortened several sections, however, no specific information was given regarding which sections should be shortened.

\section{Reviewer \#3}

1) "Spatial and temporal distribution"

Response: In accordance with Cruden \& Varnes landslide classification, a landslides distribution refers to the extension of the rupture surface in relation to the overall movement of the moving mass. Landslide state and style inform of the temporal and spatial aspects of landslide displacement.

2) “Addition of Griffith et al., 2012"

Thank you for the reference, duly added to manuscript

3) Oilseed rape is cultivated in the flat field to the north of the field site, the field to the south of the field site, in the base of the valley is commonly used for wheat.

4) "Movement initiation and historical aerial photographs"

Aerial photographs taken in 2008 and 2011 were used in the interpretation of surface characterisation methods, the most recent being 'draped' over the aerial LiDAR dataset and visualised using GeoVisionary software.

The landslide is demonstrably complex with several phases of movement having taken place since initiation. The most recent activation phase was initiated between 10-20 years ago. The current landowner has worked this area for less than a decade and as a result only an estimate of the date of activation of this phase is possible.

5) "Drilling method"

Agreed. The text has now been updated

6) Yes, fines content was determined by $x$-ray sedigraph

7) Consistency with units - have updated throughout

8) NERC or BGS

The BGS is part of the Natural Environment Research Council (NERC), which is the UK's main agency for funding and managing research, training, and knowledge exchange in the environmental sciences. 